\title{
IMPLEMENTATION OF ELEMENTS OF SUSTAINABILITY APPLIED TO THE URBANIZATION OF PRODUCTIVE AREAS
}

\author{
Carlos TURÓN ${ }^{1}$, Jordi GOMIS ${ }^{1}$
}

DOI: 10.21163/GT_2016.112.11

\begin{abstract}
:
From the perspective of urbanization, the implementation of productive areas -industrial estates, technology and logistics parks, etc.-, involves the need to incorporate solutions that provide them with greater sustainability. The specificities of these areas, such as their high energy consumption or significant water intake, means that their implementation requires the adoption of technical measures that reduce the impact on the environment, contributing to the concept of a sustainable productive area. The implementation of renewable energies and smart-grids, the improved water cycle and the introduction of urbotics are solutions that enable making these spaces more sustainable in the field of infrastructures. This article analyses and verifies their implementation in a significantly important industrial area of Spain, ultimately concluding that such elements are scarcely implemented in productive areas.
\end{abstract}

Key-words: Productive area, Urban infrastructure, Sustainability, Civil engineering.

\section{INTRODUCTION}

The design of new productive areas, -industrial estates, logistics and technology parks, etc.-, as well as their rehabilitation, poses some special considerations due to their operating requirements. From the perspective of their infrastructure and service networks, as for any other urban planning action their implementation must be rendered environmentally sustainable. In terms of urban infrastructure, the conception of urbanization has advanced little since it began to be implemented. Design criteria have evolved as the standard of living has increased and in parallel with regulations, without addressing the requirement to pursue as a priority the challenge of urban environmental sustainability (Herce \& Magrinyà, 2002).The incorporation of solutions that improve the sustainability of productive areas occurs not only due to the adoption of new technologies, but also due to the incorporation of new precepts. Thus, for example, the use of rainwater to irrigate green areas is a conceptual issue and is not conditioned by the availability of any special technology; it is simply an approach that prioritizes a minor direct investment, most often resolved by the water supply network.

There is a wide variety of examples in which poor efficiency criteria are observed, as in the case of the operation of public street lighting throughout the night when there is no traffic or pedestrians, alluding to reasons of security; or the sizing of a drainage pipes calculated to transport the water resulting from a 500-year rainfall episode, not working

\footnotetext{
${ }^{1}$ Universitat Rovira i Virgili, 43003 Tarragona, Spain, carlos.turon@urv.cat; jordi.gomis@urv.cat.
} 
properly the rest of the time due to oversizing and requiring overinvestment, failing to consider design alternatives that are conceptually adaptable to major flooding episodes. The consequences are many, all of tinged with wastage and unconscious ignorance of their high economic and ecological costs. In short, urban planning has developed against the precepts of the concept of sustainability. Proposals can be established in the design of service networks in order to maximize their effectiveness and contribute to improving the sustainability of the urbanization, the following being notable for their interest (Herce \& Miró, 2002):

- The introduction of alternative energy generation for consumption by the productive area.

- Energy-saving with different lighting levels for different spaces and times.

- The reuse of rainwater.

- Water runoff collection basins for irrigation, including the creation of discharge treatment wetlands.

- The use of technology by networks to improve the provision of urban services and the social and environmental sustainability of these services.

These proposals enable laying the foundations for the sustainable urban development of productive areas (European Commission, 2009), and it is based on such foundations that the degree of sustainability of productive areas in Spain has been verified, from the standpoint of urban infrastructure.

\section{METHODOLOGY}

The starting point of this study was to specify the different elements of sustainability that could be introduced to the urban infrastructures of productive areas. From the set of sustainability criteria established by the Green methodology (Macías \& García, 2006) -a methodology that evaluates the reduction of the impacts of buildings and their location via the implementation of measures, both in design strategies and performance factors-, investigation concentrated on measures and strategies relating to the generation of renewable energy -Criterion B.11-, rainwater retention for reuse -Criterion C.15- and the reuse of wastewater -Criterion C.16-.

Moreover, we studied the implementation of urbotic systems that enhance the management of networks fostering energy efficiency -Criterion B.9-, lower water consumption -Criterion C.14- and the optimization of networks. Having established the elements under study, we intend to verify their implementation in productive areas in Spain. Given their design and the similarity of existing regulations in the field of urban infrastructure between the different regions and provinces, a representative sample of 20 productive areas was chosen -total 600 ha-, located in an industrial environment whose epicentre is the Petrochemical Industrial Estate of Tarragona, south of Barcelona, the biggest strategic pole of the petrochemical industry in southern Europe. The sample was carried out randomly and was used to categorize the productive areas according to four different criteria:

Legal nature of the developer: public (town/city councils and public enterprises), or private developers. The sample consists of 11 public and 9 private areas. 
- $\quad$ Size of the land occupied classified into three types: large (>500,000 m2), medium (between 100,000 $\mathrm{m} 2$ and 500,000 m2), and small $(<100,000 \mathrm{~m} 2)$ productive areas. The sample consists of 3 large areas, 12 medium-sized areas, and 5 small areas.

- Predominant size of sub-parcels: areas with a predominance of large parcels (>6,000 m2), small parcels $(<6,000 \mathrm{~m} 2)$ and areas with parcels of various surface areas (mixed). The sample consists of 8 small, 8 large, and 4 mixed parcels.

- Different specializations in the activities of the productive areas: industrial estates, technology parks, business parks, etc. The sample consists of 12 industrial estates, 1 technology park, and 5 sectors of economic activities.

The analysis was carried out by checking the characteristics of their infrastructures designed by reviewing the technical urbanization projects drafted in each case. At the same time, we verified the current reality of these areas: extent of use, type of activities carried out, degree of conservation and maintenance, environmental quality, establishment of the extent of use of the infrastructures each productive area was provided with at the time, and finally, the existence of new solutions that may have improved sustainability.

\section{ELEMENTS OF SUSTAINABILITY}

Usually, In order to ensure that the urbanization of productive areas is sustainable, several aspects of urban planning must be involved. Specifically from the standpoint of their infrastructure and service networks, with regard to the design, functionality and sizing of the networks, technological and conceptual solutions can be provided that contribute to their environmental sustainability (Geohabitat, 2002). Our research is based on four elements: the generation of renewable energy for consumption in the productive area; the reuse of rainwater; the treatment and reuse of greywater; and the modernization of networks via urbotic systems which enhance network management.

\subsection{Generation of renewable energy}

The sustainability of all productive areas, given their great energy demands, involves the incorporation of renewable energy infrastructures. The emergence of renewable energy, whose costs are steadily falling, has notably changed energy flows in the electricity networks. Now customers not only consume but also produce electricity through the same network and therefore the flow of energy is now bi-directional. The possibility of consuming the electricity generated by oneself and of selling the surplus energy and/or buying the shortfall of energy, so-called self-consumption, is an interesting challenge for implementation in industrial and service activities, at the same time as promoting the use of such renewable energy.

Parallel to this is the continuous increase in the costs of electrical energy generated, transported, distributed and sold under the traditional model, at the same time that there is a willingness to reduce the use of solid fuels and the emission of toxic gases. This situation is reflected in Directive 2009/28/EC and in the legislation of the member countries establishing the path towards the reduction of toxic emissions through the increased use of renewable energy sources through self-generation, in a framework of distributed generation and self-consumption, based on the implementation of micro-networks, such as those implemented in productive areas. 
Power can be generated "in situ" in the area of consumption in various ways. The installation of photovoltaic solar panels is an interesting alternative in all areas with adequate sun hours. In productive areas this is relatively easy taking advantage of the many free spaces for general use, such as parking areas and pavements (pergola-type); or private spaces such as the roofs of buildings, large unused spaces, for the implementation of these systems. Also the generation of wind power is a good alternative, with the installation of wind turbines in green areas or open spaces.

The generation of this type of energy in the productive area itself means the production of clean, renewable and sustainable energy, in the place of consumption, enabling a little more energy independence, representing a significant change with respect to the current means of producing renewable energy in Spain. Moreover, located in industrial or service areas, the environmental impact of this type of facility is also very low. The next step to fulfil the aim of achieving efficient, safe and sustainable electricity supply includes the interconnection of the various systems -generators and consumers- in a smart manner, creating the concept known as Smart Grid (European Commission, 2016).

A smart grid can be defined as an electrical system that uses bi-directional information, secure communication technologies and computational intelligence in an integrated way across the entire spectrum of the power generation system to the points of consumption (Gharavi \& Ghafuri, 2011). In respect of renewable energy, Smart Grids are entrusted to connect the energy produced by renewable sources to the electricity network (Vicini \& Micheloud, 2012).

The term smart-grid goes beyond the concept of smart metering capable of providing detailed time-of-day billing which would allow consumers not only to choose the best rates from among the different utilities companies, but also discern between hours of consumption, improving the use of the network. This system also enables more precisely mapping consumption and better anticipating future needs at a more local level, improving energy efficiency and reliability (Gharavi \& Ghafuri, 2011). Smart Grids use innovative equipment and services that together with new technologies of communication, control, monitoring and self-diagnosis, help strengthen and automate the network, optimize the connection of areas with renewable energy sources, develop architectures of decentralized generation, improve the integration of intermittent generation and new storage technologies, and actively manage demand (Vicini \& Micheloud, 2012).

The main differences between the current system and Smart Grids is that an electromechanical, unidirectional, centralized system with very limited control due to its lack of sensors, becomes a distributed digital network, with a large number of sensors that allow precise control of installations and two-way communication (Casyaño, Franco \& Velásquez, 2014). In short, these systems allow better management of energy resources.

\subsection{The reuse of rainwater}

For years the practice of urban drainage has been quickly to channel water outside cities and developed areas. Urban waterways have been channelled and sewers designed to take all of the water from surface runoff. Because of these practices, rivers have lost their natural wealth and their ability to respond to floods, while sewerage systems are unable to absorb the amounts of additional water coming from the areas of new urban development (Gómez, 2008). Sustainable urban drainage is required to combat these problems. Rainwater that falls on urbanized spaces can be reused as it is non-polluted water that can be easily collected and piped to a location of choice. 
Depending on climatic conditions, this may involve a substantial amount, and in all cases, it allows making the absolute most of a valuable resource. This benefits both the ecology and the landscape as it can be used as a design tool and as an instrument of integration into the landscape. Some mutually compatible options for the reuse of rainwater may be established such as roof retention, stratified pond, storage tank, surface infiltration, underground infiltration or evacuation into a waterway (Busquets, 2007).

Of all the solutions described above the most interesting for application in productive areas are stratified ponds and surface infiltration, offering different technical solutions (Perales \& Andres-Domenech, 2007):

- Permeable surfaces: systems consisting of a volume of permeable material located beneath a surface that allows for the passage of water and may be grass, gravel, impermeable paving blocks with holes stuffed with grass or gravel, porous paving blocks, etc.

- Trenches and infiltration tanks: holes and ditches filled with granular material used to collect and store water runoff until infiltration into the natural terrain takes place (Fig. 1).

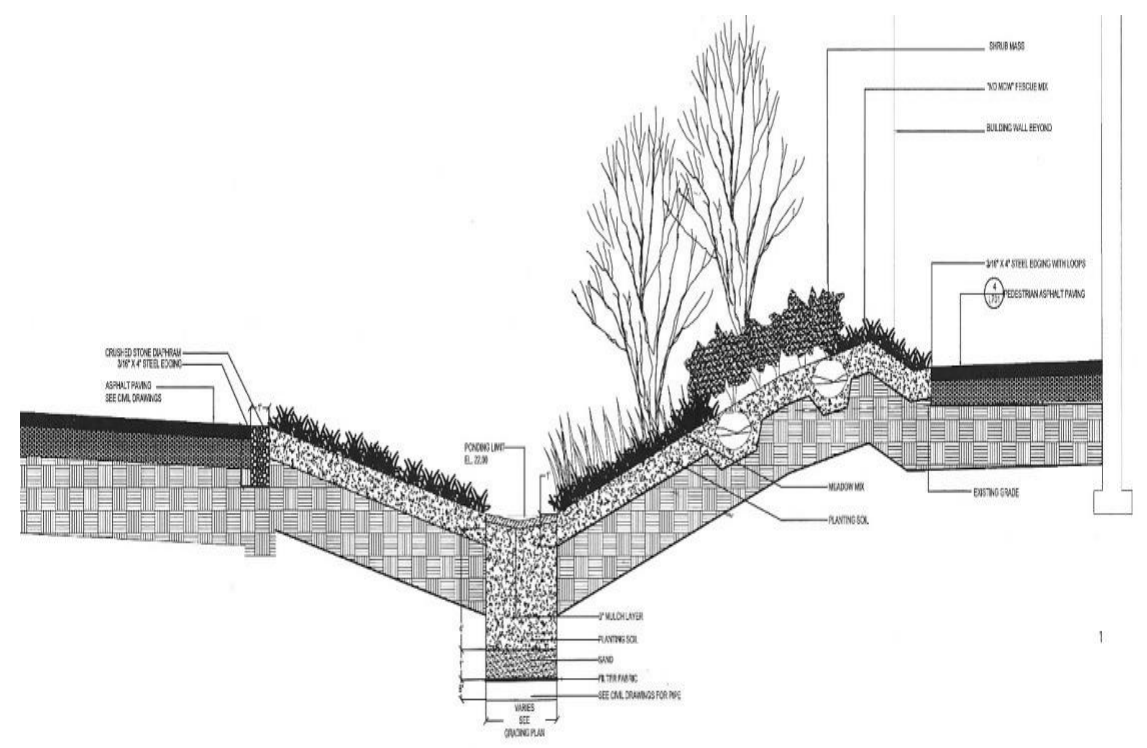

Fig. 1 Proposal for a trench drainage system at Harvard University, Cambridge, Massachusetts (Margolis \& Robinson, 2007).

- Filter drains: geotextile-coated trenches filled with gravel within which the water circulates that comes directly via a pipeline from drainage surfaces.

- $\quad$ Stratified tanks: tanks that permanently contain a certain volume of water which is evacuated according to needs into evacuation networks or irrigation channels (Fig. 2). 


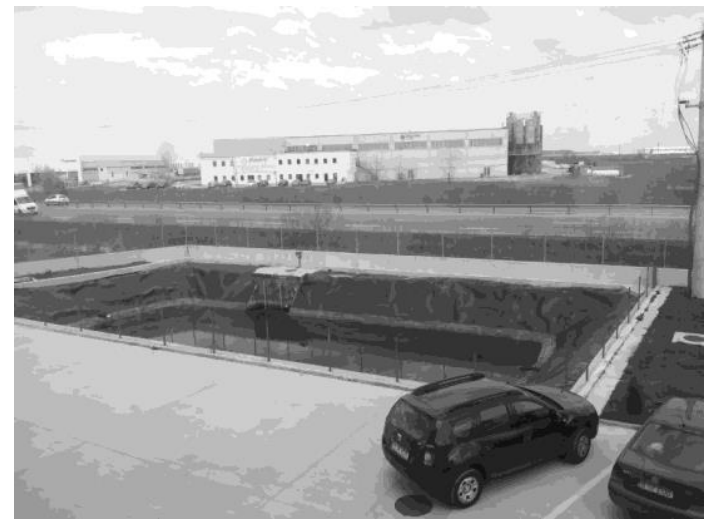

Fig. 2 Retention tank at Lebario Industrie. Bolentin Deal. Romania (authors' archive).

- Collection of rainwater from surfaces and creation of continuous tree grates feeding from the collected water (Fig. 3).
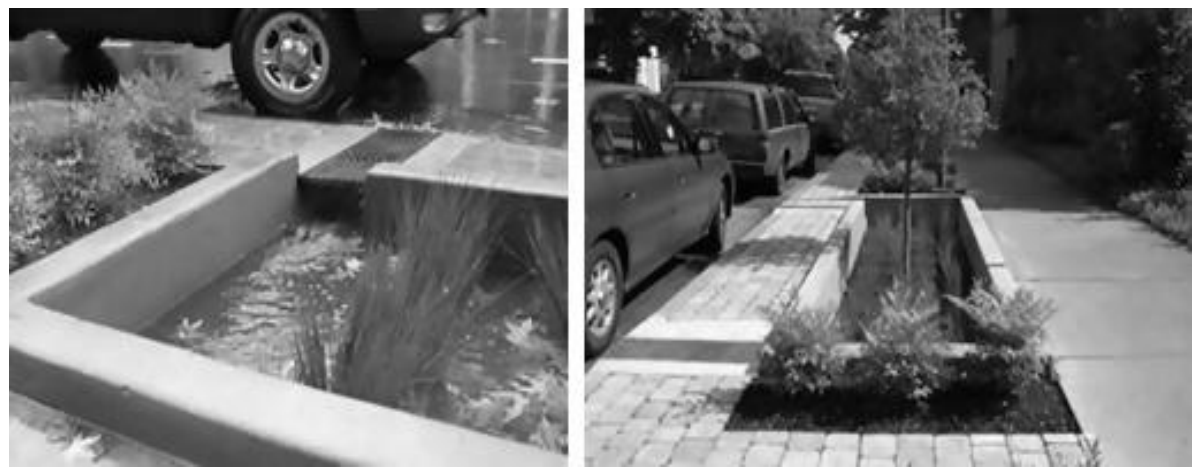

Fig. 3 Proposed drainage system on SW 12th Avenue Green Street, Portland, Oregon (Portland Bureau of Environmental Services, 2016).

The wide variety of existing alternatives suggests that any surface is susceptible to becoming a water recovery element, ditches can be grass instead of concrete, green areas can have a pond, any strip of land can become a filter strip. All that is required is the will to implement the change (Castro et al, 2005). The above solutions, on the one hand, will allow sizing rainwater pipes with lower flow rates and intensities, achieving smaller diameters with the consequent reduction in investment. On the other hand, clean water can be taken advantage of, improving the moisture of the subsoil in areas where paved surfaces are widespread. 


\subsection{Reuse of greywater.}

The treatment of greywater (without bacteria) is an interesting way to reduce potable water consumption. Recovered greywater is considered non-potable and is therefore typically used in applications such as toilets, irrigation and cleaning. The use of greywater recovered for such purposes can be estimated to reduce the total drinking water consumed by approximately $30 \%$ (Larsen \& Mauer, 2011). An alternative to conventional treatment systems used for the treatment of greywater, useful in productive areas due to the large amount of space available for its implementation, is treatment using systems based on biological processes for cleaning polluted water. Biological water treatment, or phytodepuration, is based on the natural ability of some plants to absorb or degrade toxic substances or pollutants (Ferrara, 2013). It is an efficient and low cost alternative, both as regards maintenance and implementation compared with traditional systems. In addition, it can promote the landscape integration of green areas in the productive area. For the treatment of greywater using natural methods, the following technical solutions are available:

- Lagooning: a system that uses an artificially constructed lagoon or series of lagoons. They stabilize organic matter via physico-chemical and biological processes produced by algae and bacteria.

- Green filters: based on the application of a controlled flow of wastewater on the ground surface, where a forest stand or crop has been planted. Treatment is performed by the joint action of the soil, microorganisms and plants via a triple action: physical (filtration), chemical (ion exchange, precipitation and coprecipitation, redox phenomena) and biological (degradation of organic matter).

- Wetlands: monoculture or polyculture of higher plants (macrophytes) arranged in lagoons, tanks or shallow channels, like natural wetlands.

\subsection{Urbotics.}

The implementation of urbotics -electronics technologies, automation, information technology and telecommunications- in productive areas, allows improving the design and provision of urban services, better social and environmental sustainability of these services, and more efficient management thereof (Barberis, 2010). Urbotics poses the extension of high capillarity communication networks, and the mass implementation of sensors and actuators, which by way of a nervous system and using towns' and cities' urban furniture, paving, tree plantations or any other element of public space, allow influencing the automation and smart management of urban services. The result of the implementation of urbotic resources, drawing an analogy with the Smart City, could be called the Smart Business Park. The availability of real-time and deferred information and the capacity to act improves the management of structural services and reduces management costs and the environmental impact they generate. Networks of sensors and communication devices and a management platform comprise the technology ecosystem needed to acquire information on what is happening in an environment or space, store it, and make it available to managers and users through either existing or newly created end-use applications, enabling acting in the urban space in real time (Colado, Gutiérrez \& Vives, 2013). In productive areas, the urbotic systems of greatest interest in the management of urban infrastructures are those applied to drinking water distribution management, drainage network management, and the management of electric power and public lighting networks. 


\subsubsection{Distribution of drinking water}

The real-time control (RTC) system enhances the operation of the facilities as it allows ascertaining the variables reporting on the status of the network (flow rates, pressure, free chlorine concentrations, etc.), provided by adequate instrumentation to ensure reliability; knowing the operational status of the elements and equipment within drinking water production and pumping centres; modifying the settings of elements that perform in automatic mode; and, handling certain elements of the network operation remotely (valves, pumps, etc.). The data harnessed in real time for each of the remote stations are collected, managed and displayed at a Control Centre. In addition to its actual management, the information obtained permits analysis in the event that the service is disrupted; such information may be used to produce and update mathematical models of the drinking water distribution networks; perform maintenance management; and ensure quality and continuous improvement in process management. The use of remote telemetering systems with the use of electronic meters that provide extended data is the option that provides the greatest added value in the processes of supply networks management since it enables controlling the water resource more efficiently as it allows knowing how consumption is taking place, as well as optimizing customer spending given that, according to the data supplied, leaks can be detected and, as they can be fixed quickly, savings are promoted (Gómez-González et al, 2011).

\subsubsection{Water drainage}

The management of water drainage networks can be performed in a similar way to the management of water supply networks. Sewer networks have traditionally operated almost unaltered, which means they provide a single solution for the demands made on the system, whether the flow is rainwater, wastewater, for water treatment or possible reuse. They are designed for a steady load called rain intensity, of a known length of time and evenly distributed in space. However, the distribution of rain is non-uniform in space and depending on the size of the system, it can vary greatly depending on the area, and so in a rain episode it is possible that there will be areas heavily overloaded and others far below their operative capacity.

The implementation of RTC in a water drainage network completely changes its management capabilities converting a system that is by definition static into one that behaves dynamically, allowing obtaining a number of clear advantages in terms of its operation (Mata, Alamo \& Gil, 2006): avoiding flooding by taking advantage of the network's storage potential; reducing the effects of pollution, by allowing the temporary storage of the first washing of the basins for their subsequent treatment at the treatment plant; reducing the suspended solids to be treated by the treatment plant, by allowing settlement in retention tanks; and, finally, designing a network under non-static loading conditions, with a reduction of pipe diameters.

\subsubsection{Electrical energy supply}

The proper functioning of Smart Grids is thanks to the real-time control of the electrical consumption of each subscriber, making remote metering and the sending of this information to a central computer essential. Hence there is a need for electronic meters whose functionalities provide a number of advantages to the management of such networks: the remote control of consumption via the same electrical wiring that transmits electricity; remote firmware upgrading to incorporate new functionalities, more measured parameters, the control of the power demanded; and the management of supply connection/disconnection, among others. 
The use of smart meters allows consumers to receive information about their consumption habits and the associated electricity price. With this information, they can adapt their patterns of consumption, consuming at off-peak times. The result is an increase in the efficiency of energy use, reduced peak demand (between 10 and 20\%), a reduction in depth during periods of less demand, and a positive effect on sustainability by reducing costs and carbon emissions (Sánchez de Miguel et al, 2011).

\subsubsection{Street lighting}

One very important aspect to be taken into account in the design of lighting is not just the degree of illumination and light pollution but also the cost of maintenance, which has increased in recent years in Spain and is now the highest of the major countries of the European Union, as shown in Fig. 4 (Sánchez de Miguel et al, 2011).

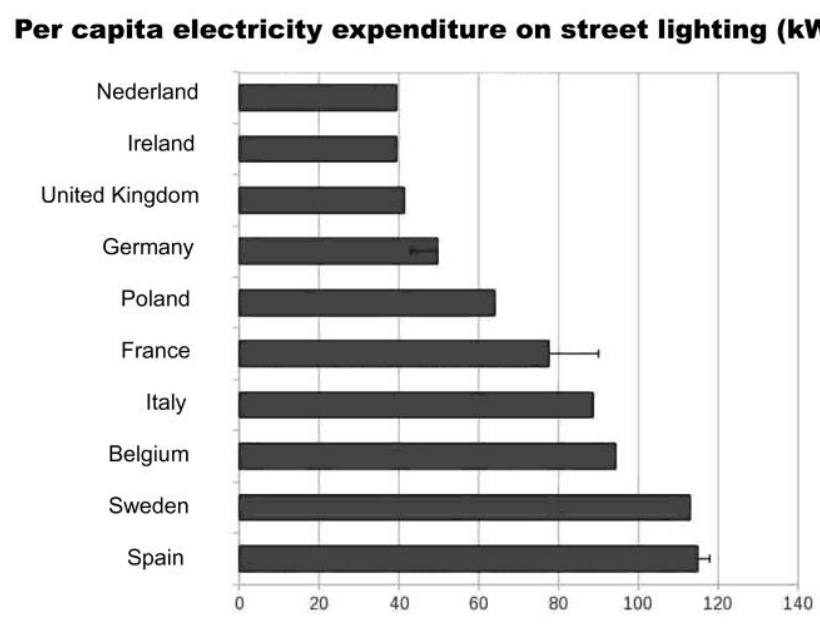

Fig. 4 Per capita electricity expenditure on street lighting (kWh/year).

Meshed telemanagement enables reducing the invoice paid to the utility company for public lighting, consuming less. Broadly speaking, it consists of installing in each lamppost a device that enables controlling the intensity of the lighting of each light source, either preset or in real time, online. In the first case it would decrease by a set percentage as of a certain time of day. For example, as of midnight the lights would operate at $40 \%$ capacity, with the consequent energy saving (Barón, 2011). In the second, control would be from a computer that allows an operator direct control, in real time, of each of the light sources. Thus, the light intensity of a lamppost could be reduced at a given time and, at the same time, that of the adjacent lamppost increased.

The emergence of new types of bulb, for example LED, with much lower power consumption, and with the possibility of switching on/off immediately, allow new possibilities in this area. It is no longer necessary for lighting to operate throughout the night. Instead it can come on when the movement of cars or people is detected in a street, with the consequent immediate real savings. In addition, given these lamps' reduced consumption they can be powered by photovoltaic panels installed on the post or lamp. 


\section{ANALYSIS AND RESULTS}

The analysis performed was based on verifying the implementation of renewable energy generation facilities, the reuse of grey and rainwater, and on the implementation of urbotic systems to improve sustainability. The technical projects have been reviewed that originally served as a basis for the execution of the building works, and the current state of their infrastructures and the operation of each area were ascertained.

Renewable energy generation:

In $80 \%$ of the productive areas studied there are private renewable energy facilities generating photovoltaic energy, mainly installed on the roofs of the buildings, though with a negligible power capacity when compared to total needs. There are no wind farms, in spite of the good wind conditions at some of the locations studied. Finally, neither have public spaces been taken advantage of for the implementation of these power-generating facilities. Additionally, small cogeneration facilities have been seen to produce electricity in many of the industrial estates analysed.

Interestingly, productive areas with private renewable energy generation facilities remain, without any major quantitative variations worthy of mention, within the categorizations that have been established according to the legal nature of the developer, the size of the facility, the size of the parcel or the specialization of the productive area.

\section{Reuse of grey and rainwater:}

In this area the results are totally negative. No area was found with to make any use whatsoever of grey or rainwater, not for irrigation, or for supplying the productive processes, or for cleaning, etc. In all cases, greywater is treated and sent to channels of various types in the same way as rainwater. In around $15 \%$ of the study sample rainwater infiltration solutions have been implemented to enable keeping the ground minimally moist.

\section{Urbotics:}

Urbotic systems are available primarily in the distribution of drinking water $(60 \%$ of the sample), with remote network control, and also in street lighting via systems to reduce energy consumption (100\% of the sample), based on reducing light output after a certain time of the day/night, although no progress has been made in the field of replacing luminaires with LEDs or other lower consumption systems and more efficient management. With regard to remote control systems for drinking water distribution networks, they are not linked to any of the categorizations established and their implementation is completely random from this point of view. However, this implementation was detected to be linked with the conditions of urbanization required by the local municipality in question or by the utilities companies. No solutions are implemented in water drainage networks or in electricity distribution networks.

The installation of fibre optics as one of the elements of communications and support for urbotic systems is non-existent. Finally, we would emphasize that no sufficiently significant differences have been appreciated in the results obtained from the sample, according to the legal nature of the developer. The results do not differ between the productive areas developed by public institutions and those developed by private institutions, and this can be seen as being a particularly relevant issue. 


\section{CONCLUSION}

The In Spain, urban development projects for productive areas must, in accordance with the regulations promulgated primarily between 1975 and 1980, be provided with paving infrastructure, a water supply network, sewers, and electrical power distribution and public lighting networks. Productive areas are designed to accommodate such mandatory infrastructures, operating, after running for years, in the same way as they were originally designed to operate, offering no dynamism regarding modifications to the initial construction, whether due to new needs or adaptation to social or legal changes. In order to improve the sustainability of a productive area, from the point of view of its urban infrastructure, proven technical solutions exist for each of the basic networks (water supply, wastewater disposal, electricity distribution network and street lighting). In some cases the technical solutions are technological in nature and therefore their application is either recent or future, while in others they are solutions that have always been applicable but of which in practice little use has been made, such as holding tanks to reduce rainwater drainage pipe sizing and also to take advantage of such water for other uses.

The development or adaptation of infrastructure, which would improve the sustainability of productive areas, is seen to be non-existent. The improvement of the water cycle, the generation of renewable energy in the areas themselves, the installation of street lighting consuming less power, urbotics, etc., are aspects whose implementation would improve the operation of the areas and improve their sustainability, adapting to the new social and economic realities that enterprises demand. In Spain, there is a general need for updating and improving the infrastructure and the environmental conditions of the existing productive areas, either with the support of the administration and/or of the companies established in them. It is, in fact, the latter who, in the final analysis, know of the issues of the day to day and they are the first to be aware of the importance of having a modern space in which to carry out economic activities that boost the emergence of external economies.

Finally, consideration should be given to the concept of a productive space or area today, where there are a number of companies that act independently, paying costs to the municipality and to the utilities companies having absolutely nothing to do with such concepts as savings, efficiency or sustainability. The application and adaptation of a concept of holistic needs management, where all of the enterprises can take advantage of this new aspect of sustainability, by way of small "Smart Cities", generating and consuming electrical power and selling or buying the surplus in micronetworks, making use of rainwater, sharing surveillance services, and many other services that can be provided jointly, would improve yields, reduce costs and lead to coexisting in a far more pleasant environment.

\section{ACKNOWLEDGEMENTS}

The authors would like to acknowledge financial support from the Spanish Government (ENE2015-64117-C5-3-R, MINECO/FEDER, UE).

\section{R E F E R E N C E S}

Castro, D., Bayón, J. R., Rodríguez, J. \& Ballester, F. (2005) Sistemas urbanos de drenaje sostenible. Interciencia, 30 (5), 255-260.

Barberis, W. (2010) Ciudad urbótica contemporánea: urbanística y nuevas tecnologías al servicio de la calidad del espacio y los servicios urbanos. International Conference Virtual City and 
Territory, Mexico, 2010. [Online] Available at: http://upcommons.upc.edu/handle/2099/12846 [Accessed on 6 March 2016].

Barón, R. (2011) Alumbrado público y sostenibilidad. Revista Física y Sociedad, Colegio Oficial de Físicos, 21, 23-26.

Busquets, J. (2007) Buenas prácticas de paisaje: Líneas guía. Barcelona: Generalitat de Catalunya, Departament de Política Territorial i Obres Públiques.

Casyaño, J. H., Franco, C. C. J. \& Velásquez H. J. D. (2014) Smart meters adoption: Recent advances and future. Dyna Colombia, 183, 221-230.

Colado, S., Gutiérrez, A. \& Vives, C. J. (2013) Smart city: Hacia la gestión inteligente. Barcelona: Marcombo.

European Commission (2009) Promoting sustainable urban development in Europe, Achievements and opportunities. Brussels: Directorate-General for Regional and Urban Policy.

European Commission (2016) European Smart Grids Technology Platform. Brussels. [Online] Available at: http://www.smartgrids.eu/ [Accessed on 3 March 2016].

Ferrara, L. (2013) Phytodepuration process for the recycling of wastewater in dairy. 1st Annual International Interdisciplinary Conference, Azores, Portugal 2013. [Online] Available at: http://eujournal.org/files/journals/1/books/aiic.vol.3.pdf [Accessed on 6 March 2016].

Geohabitat (2002) Manual de diseño. La ciudad sostenible. Madrid: Ministerio de Economía-Instituto para la Diversificación y Ahorro de la Energia.

Gharavi, H. \& Ghafuri, R. (2011) Smart Grid: The Electric Energy System of the Future. Proceedings of the IEEE, 99 (6), 917-921.

Gómez, M. (2008) Curso de hidrología urbana. Barcelona: Distribuidora Alfambra de Papelería.

Gómez-González, A., Chanampa, M., Morgado, I., Acha, C., Bedoya, C. \& Neila, J. (2011) Cubiertas planas fitodepuradoras. Propuesta de gestion de aguas grises en altura. Informes de la construcción, 61-71.

Herce, M. \& Magrinyà, F. (2002) La Ingeniería en la evolución de la urbanística. Barcelona: Edicions UPC.

Herce, M. \& Miró, J. (2002) El soporte infraestructural de la ciudad. Barcelona: Edicions UPC.

Larsen, T. A. \& Mauer, M. (2011) Source separation and decentralization. Treatise on Water Science, 4, 203-229.

Macías, M. \& García, J. (2006) Metodología y herramienta VERDE para la evaluación de la sostenibilidad en edificios. Informes de la Construcción, 62, 87-100.

Margolis, L. \& Robinson, A. (2007) Living systems: Innovative materials and technologies for landscape architecture. Basel: Birkhäuser.

Mata, R. I., Alamo, M. J. \& Gil, R. B. (2006) Gestión centralizada de aguas residuales en polígonos industriales: Una estrategia sostenible. Ingeniería Química, 38, 435, 135-143

Perales, S. \& Andres-Domenech, I. (2007) Los sistemas urbanos de drenaje sostenible: Una alternativa a la gestión del agua de lluvia. Barcelona: Equipamientos y Servicios Urbanos Municipales.

Portland Bureau of Environmental Services (2016). City of Porland, Oregon. [Online] Available at: $\mathrm{http} / / / \mathrm{www}$.portlandonline.com/bes/index.cfm?a=123776\&c=45386 [Accessed on 3 March 2016].

Sánchez de Miguel, A., Zamorano Calvo, J., Mosquera de Arancibia, A. \& Almazán González, M. (2011) El alumbrado público español, el mayor gasto eléctrico por habitante en Europa. Universidad Complutense de Madrid. [Online] Available at: http://eprints.ucm.es/25949/ [Accessed on 6 March 2016].

Vicini, R. A. \& Micheloud, O. (2012) Smart grid: Fundamentos, tecnologías y aplicaciones. México D.F., Cengage Learning-Tecnológico de Monterrey. 